The Voluntary Food Intake of Pigs

Occasional Publication No. 13-British Society of Animal Production 1989

edited by J. M. Forbes, M. A. Varley and T. L. J. Lawrence

\title{
COMPARISON OF THE PERFORMANCE OF FINISHING PIGS FED AD LIBITUM FROM EITHER CONVENTIONAL OR SINGLE-PLACE FEEDERS
}

\author{
A. J. WALKER \\ MAFF/ADAS, Block B, Government Buildings, Brooklands Avenue, Cambridge CB2 2DR \\ and \\ D. C. OVERTON
}

Wildermere Farm, Holywell Row, Bury St Edmunds IP28 8NB

\section{INTRODUCTION}

G ood husbandry practices for the management of the ad libitum fed finishing pig have traditionally included ample provision of trough space. However, for several years commercial pig producers in Denmark and the Netherlands have been successfully finishing pigs using hoppers that only allow one pig to feed at a time. Following the introduction of single-place ad libitum feeders on to a commercial pig farm in Suffolk, two trials were undertaken to investigate the effect on finishing pig performance of reducing trough space allowances.

\section{METHODS}

Each trial used two pens of 18 gilts and two pens of 18 boars. The pigs were housed in a part-slatted finishing house with a high-speed jet ventilation system. Each pen

TABLE 1

Trial 1

Weight at start $(\mathrm{kg})$

Weight at finish $(\mathrm{kg})$

Daily live-weight gain (g/day)

Food conversion efficiency

Carcass weight $(\mathrm{kg})$

Backfat at $\mathrm{P}_{1}+\mathrm{P}_{3}(\mathrm{~mm})$
Conventional feeder

Mean
$30 \cdot 1$
$82 \cdot 9$
747
$2 \cdot 58$
$63 \cdot 2$
33

TABLE 2

Trial 2

Conventional feeder

Weight at start $(\mathrm{kg})$

Weight at finish $(\mathrm{kg})$

Daily live-weight gain (g/day)

Food conversion efficiency

Carcass weight $(\mathrm{kg})$

Backfat at $\mathrm{P}_{2}(\mathrm{~mm})$

$\overbrace{\text { Mean s.e. }}$

$49 \cdot 7$

$82 \cdot 4$

800

$2 \cdot 98$

$64 \cdot 5$

$12 \cdot 7$

\section{s.e.}

$1 \cdot 17$

12

$0 \cdot 16$

0.89

0.87
Single-place feeder

$\begin{array}{cc}\text { Mean } & \text { s.e. } \\ 31 \cdot 3 & 0.58 \\ 84 \cdot 4 & 1.25 \\ 758 & 15 \\ 2.35 & 0.05 \\ 65 \cdot 1 & 1.03 \\ 31 & 0.91\end{array}$

Single-place feeder

\begin{tabular}{cc}
\hline Mean & s.e. \\
44.7 & 0.57 \\
79.6 & 0.76 \\
820 & 13 \\
2.49 & 0.03 \\
60.9 & 0.66 \\
11.6 & 0.47
\end{tabular}


of pigs was allocated either a conventional feeder or a single-place feeder which provided $1800 \mathrm{~mm}$ or $300 \mathrm{~mm}$ of trough space respectively. The hoppers were positioned in the lying area adjacent to the feeding passage. The pigs were fed a pelleted compound finishing ration containing approximately $50 \mathrm{~g}$ oil and $210 \mathrm{~g}$ crude protein per kg. Records were made of individual weights at start and finish, carcass weight, backfat at slaughter and the food offered to each pen.

\section{RESULTS}

The results are shown in Tables 1 and 2 .

In neither trial were the results for the pigs fed from the single-place feeder significantly different from those for pigs fed from a conventional hopper. Furthermore no effect due to treatment was observed in the variation of growth rates within each pen. It was felt that the increased wastage from the conventional feeder may be responsible for the difference in food conversion efficiences observed.

\section{CONCLUSIONS}

The provision of a single-place feeder instead of a conventional ad libitum feeder did not have a detrimental effect on finishing pig performance. These findings may be useful to commercial pig producers, as feeders occupy valuable floor space in pig housing. 